\title{
Applications Of Mathematical-Oriented Elements And Approaches In Civil Engineering: A Critical Review
}

\author{
Lovneesh Sharma1, Pankaj Kumar Mishra² \\ ${ }^{1}$ Civil Engineering Department, Chandigarh University \\ ${ }^{2}$ Mathematics Department, Chandigarh University \\ ${ }^{1}$ lovneeshsharma39@gmail.com, 22pankaj030878@gmail.com
}

Article History: Received: 11 January 2021; Accepted: 27 February 2021; Published online: 5 April 2021

\begin{abstract}
The rapid technological modernization in civil engineering is diligentlyconnected to the interdependenceamongst mathematics and civil engineering. This demands civil professionals be more competent and trustworthy in their mathematical and engineering abilities. This paper reviews the tendencies of engineering complications that involvemathematical-oriented fundamentals. Introductions to the civil engineers at the place of workproposeunderstandings of the nature of complications in the actualbackground and an examination of the mathematical-oriented fundamentals in cracking these difficulties. The findings recommendthat the mathematicalinformative endeavours assimilatetrustworthy problem-solving understandings for civil engineering scholars. Functioning research is one of the modernsubdivisions of practical mathematics. Due to the extensive applicability and substantialusefulness, its expansion became significant, the business revolution and the spectacular growth of the calculationprocedure had animportant role. The operative research deals with the resilience of afinestconclusion as a symbol of the defrayal of deterministic and stochastic depictionsorganized for the learning of monetary andorganizationalspectacles. From a rationalmethodology, the development of the elaboration of a conclusion is edged by numerous decisional prototypes, as well as the eminence quodictating the settlement commissioning a result is measured by the volume, erection and excellence of the existingdata. Subsequently, the supervisors may use mathematical prototypes of optimization which are supportive for captivating a conclusion under the conditions of reliability, which means all importantessentials are known, as following: Decisional imitation; Decisional board; thepractice of global utility. In most of the subjectsacknowledged, it is assetobserving that the use of mathematics is extensively applied in civil and structural engineering complications. The uncontaminated mathematical connotations seem to be subliminallysecreted and entrenched behind the 'civil and structural' of the complications, but it remains appropriate to know whereverdiagnostic results originated from. Therefore, it can beaccomplished that the mathematics-oriented acutethoughtfulfundamentals are suggestivelyrequired to crackseveral civil engineering places of work problems.
\end{abstract}

Keywords: Civil Engineering, Mathematics, vibration analysis, hydraulic analysis, Calculus, Differential

\section{Introduction}

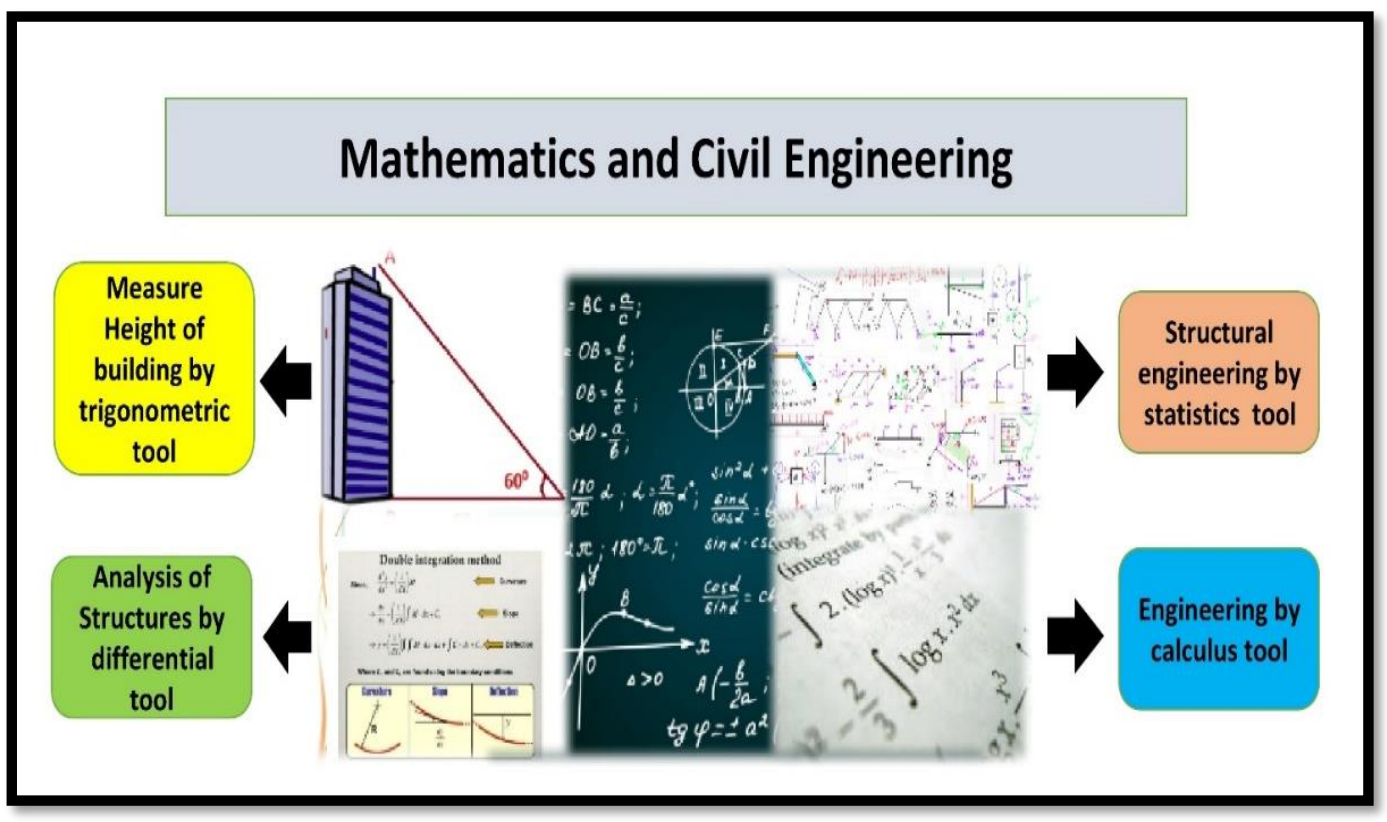

Civil engineering is the solicitation of bodily and methodicalphilosophies for cracking the difficulties of civilization, and its past is complicatedlyrelated to developments in the accepting of physical science and arithmetic throughout the history. For the reason that civil engineering is a comprehensiveline of work, countingnumerousspecified sub-disciplines, its antiquity is connected to the acquaintance of buildings, constituent's science, earths, hydrology, ecological science, mechanics, task management, and supplementaryarenas 
All overprehistoric and primitive history maximum architectural projects and structures were carried out by craftsperson, such as stonemasons and carpenters, mounting to the protagonist of chiefconstructer. Acquaintance was then reserved in associations and seldom succeeded by progresses. Constructions, transportations, and groundwork that are still existed were monotonous, and upsurges in scale remained incremental.One of the most primitiveillustrations of a technicaltactic to bodily and scientificglitchespertinent to civil engineering is the effort of Archimedes in the 4th century,counting Archimedes Principle that reinforces our understanding of resilience, and real-world explanations such as Archimedes screw.

In this modern era, Civil Engineers plays a very important role to construct the irregular shape or seismicresistant building. It has many branches like Structural Engineering, Transportation Engineering, and ConstructionManagement Technology Engineering etc. Although Mathematics is the mother of all the sciences and is the spirit of engineering. In this work, we have studied the aspects of structural designing which has a wide application for the numerical and actuarial sciences. Structural engineerscreate the structures, modern plants and transportation foundation(Jain). In various Nations, the urban communities have more focus on practical structure and shielding foundations to avoid the harm brought by cataclysmic events. Hence the earthquake-resistant structural designing attracts more appreciations from the communities. We have also studied mathematics in hydraulic engineering, wherein fluid mechanics the parameters like the movement of the liquid molecule, kind of stream, energy condition, congruity condition, speed potential and stream work etc. are all characterized by the use of arithmetic. These parameters also determined by utilizing the eulerian and Lagrangian approach. In a basic investigation, the limited component technique is valuable for assessment of multistory structures, plan of inflexible asphalts for streets and assessment of molecule under different sort of powers like seismic power, wind power. Different programming of investigating of common structures depend on FEM technique for examination like STAAD.PRO, ETABS, Ansys, and SAP2000. Huge numbers of significant hypotheses of designing mechanics like Lami's hypothesis, Varignon's hypothesis, Euler's hypothesis and so forth are the key apparatuses for investigating of particles in rest or just as moving under the activity of outer powers(Beardmore, Peletier, Budd, \& Wadee). Likewise, in deciding of different properties like region, volume, centroid, a snapshot of latency, range of gyration, slimness proportion and so forth of various segments like square shape, triangle, circle and compound segment arithmetic had assumed essential job(Yang).

\section{Mathematics helps to improve the structuralbehaviour in loading conditions:}

In the reaction of structures under stacking/loading conditions, there is the various origin of nonlinearities. In any case, for the reason thus the different cases can be gathered into two particular classes: (1) material and (2) mathematical nonlinearities. The origin of nonlinear material conduct can emerge from the reaction where the constitutive law (relating pressure to strain) in the flexible reach isn't straight - named nonlinear flexibility. Materials, such as mild steel have a direct versatile/elastic constitutive law, yet other significant auxiliary materials, solid, aluminium, and combinations of iron, for example, tempered steel are all models where the flexible constitutive law is nonlinear (Wadee)(Yang).

Another course to nonlinearity in the material reaction can happen even in direct flexible materials when the pressure exceeds so-called yield pressure or yield stress; permanent distortion (plasticity) follows and the constitutive law leaves from the underlying straight relationship (Fig. 1). For fragile materials, for example, solid metal or cast iron, crack, instead of plasticity, follows the elastic reaction; a further case of material nonlinearities administering the mechanical reaction during failure(Wadee \& Edmunds).

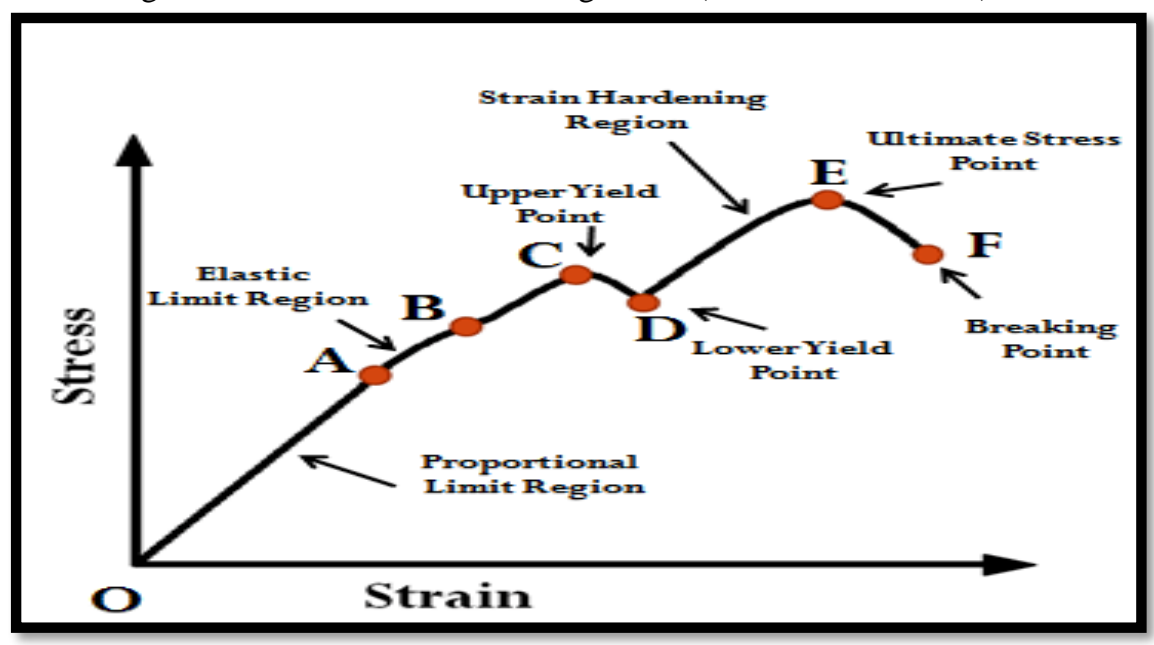

Figure 1: Stress-Strain Relationship for Mild Steel or Ductile Material https://images.app.goo.gl/wh7bEYgrceVeWynn 
The above Figureindicates Stress-Strain Curve aimed at Mild steel or Ductile Solid when a solidexperiences Tensile Test. On X-direction, we have Strained and on Y direction we have Stressed. The curve starts from point O. Consequently,there is no Stress and Strain on primary point $\mathrm{O}$. The succeeding are the numerousphases through which the mild steel / ductile solid passes over the stress-strain curve as presented in figure 2 and 3(Huh, Lim, \& Park).
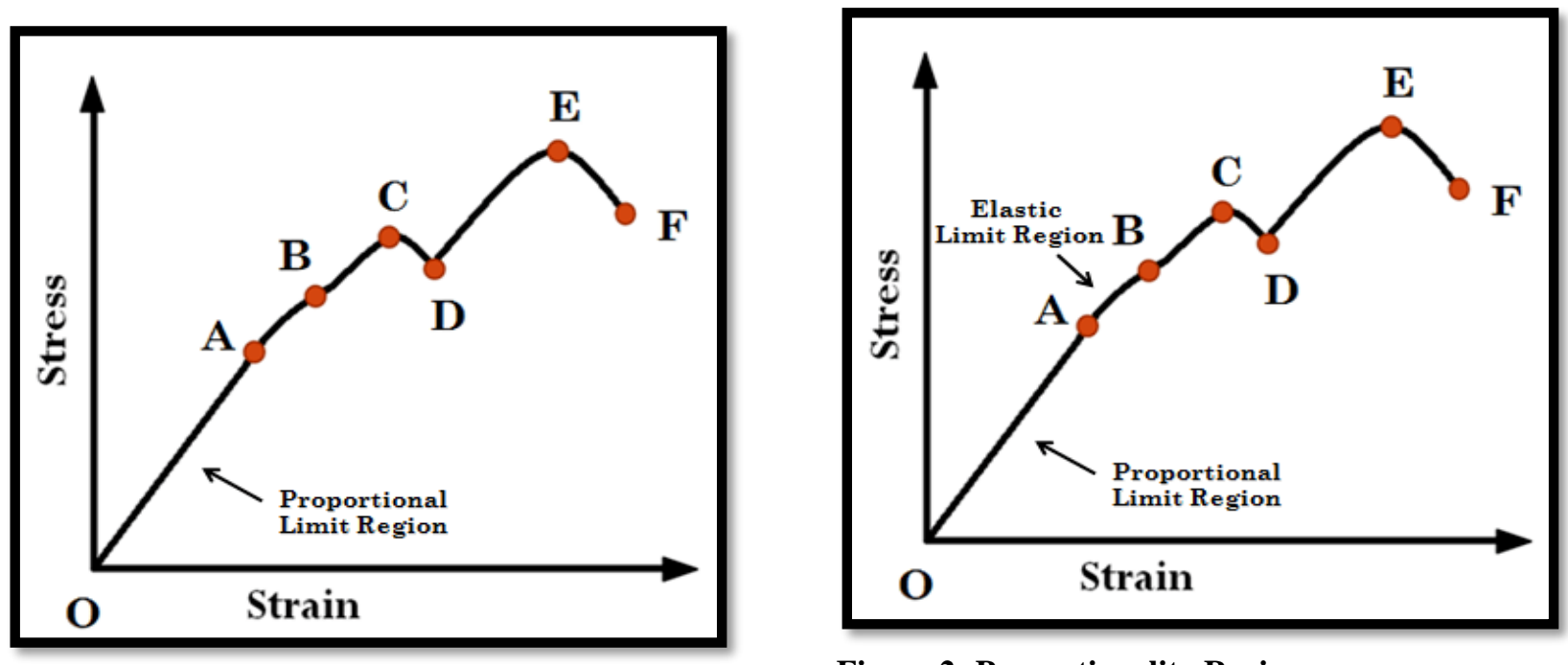

Figure 3: Elastic Limit Region

https://www.basicmech.in/stress-strain-curve-for-mild-steel/\#1Proportional_Limit_Region

\section{Uses of mathematics in civil engineering:}

Structural designing coursework includes the use of numerical mathematics standards and abilities to genuine issues. Classes, such as, Structural engineering which analyze the structures like trusses, pillars and beams, and concepts like Virtual work, energy strategies and impact lines. In Mechanics of Solids investigating incorporates the points like internal forces and deformation in structural elements, stresses, theories of columns, and segment hypothesis. In liquid mechanics the investigations like properties of liquids, liquid elements and dynamic comparability to break down the progression of compressible and incompressible liquids in closed channels. These classes apply the standards and abilities learned in the essential mathematics courses.

\section{Different approaches of mathematics in civil engineering:}

1. CALCULUS APPROACH: As is notable, the nonlinear Schrodinger conditions (NLSs) play a significant function in quantum mechanics (Karakashian \& Makridakis)(Li, Huang, \& Wang). During the previous years, there are different mathematical techniques in the mathematical investigation and logical figuring for NLSs as of late, as the speculation of the standard nonlinear Schrodinger equation, there have been developing interests in the examination and processing for the mathematical answers for nonlinear fragmentary Schrodinger conditions (FSEs) (Li et al.)(Wang, Guo, \& Xu).

The rate of displacement, velocity and acceleration in terms of time can be determined as shown in figure 2 . Another approach is calculus, to find out the Use of Fractional Calculus for Dynamic Problems of Solid Mechanics. In this study the dynamic conduct of straight and nonlinear 1DOF frameworks, frameworks with two and more DOFs, just as direct and nonlinear frameworks with a limitless number of levels of opportunity: vibrations of poles, radiates, plates, shells, suspension joined frameworks and multilayered frameworks. Effect reaction of viscoelastic bars and plates is considered too. The outcomes got in the field are fundamentally assessed in the light of the current perspective on the spot and part of the partial analytics in designing issues and practice. (Rossikhin \& Shitikova).

Another example, overall steady stream rate arrangement, which is material to entirety spatio-worldly ranges, is inferred utilizing the Fox H-work. Affectability examinations were vehicle tried out for different cases. The arrangement created here grants the utilization of early creation information (Aydinlik \& Kiris).

By consolidating early and late time information, it is conceivable to decide the two fractal measurements independently. From the natural property of the Fox H-work, this model makes it conceivable to catch the set of experiences and nonlocality of transport. Along these lines, the model favourable to vides an overall strategy for describing the weight conduct of fractally broke supplies (Park, Choe, \& Kang). 


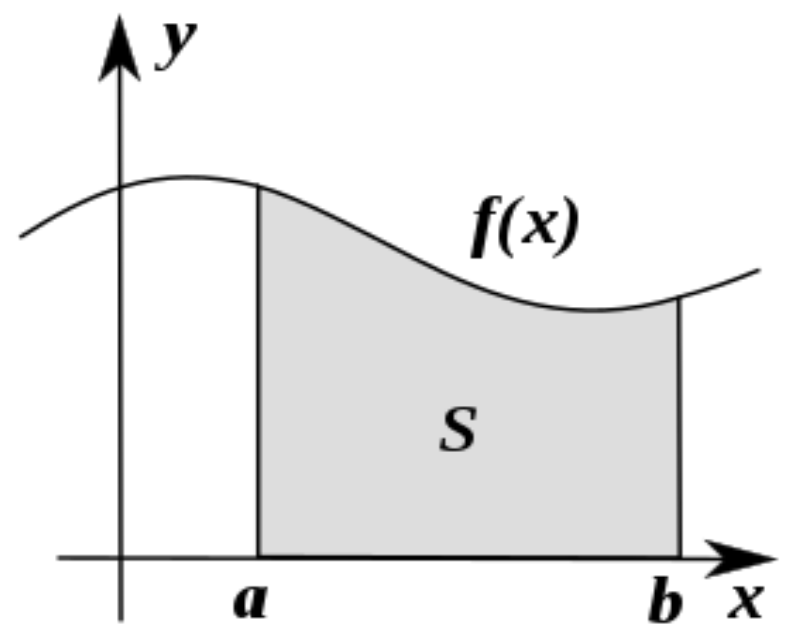

Figure 4: Application of Calculus Approach in Civil Field https://images.app.goo.gl/NXCt4Kq19wnFRFzr7

\section{TRIGONOMETRIC APPROACH:}

By using trigonometric methods, civil engineers help to find out the angles and elevation of any building. They calculated the angles and height of the building by various theorems like Pythagoras theorem and triangles methods theorem(Berton). The consequence of designing work demonstrates that the proposed technique can help the assessor outstanding burden and improve the exactness of conclusive qualities somewhat contrasted and normal geometrical levelling techniques. The technique can be utilized in applications in which two benchmarks are far and mounting a level in the centre place is outlandish, for example, levelling across waterways, ravines, oceans, or thick woods (Xu, Chen, Guan, \& Zhou).

Pressure driven conductivity is a basic hydrogeological boundary, who's in situ estimation at a neighbourhood scale is performed through infusion tests from screened tests or utilizing impermeable packers in screened wells(Ceylan \& Baykal).

The shape factor $\mathrm{F}[\mathrm{L}]$ is a proportionality steady needed to gauge conductivity from flow stream rate to infusion head proportions, and it relies upon the mathematical properties of the stream field(Peursem, Zlotnik, \& Ladder).

Existing approaches for assurance of $\mathrm{F}$ are either founded on mathematical or numerical improvements and are restricted to specific suspicions about the stream area's outer limits(Klammler, Hatfield, Nemer, \& Mathias).

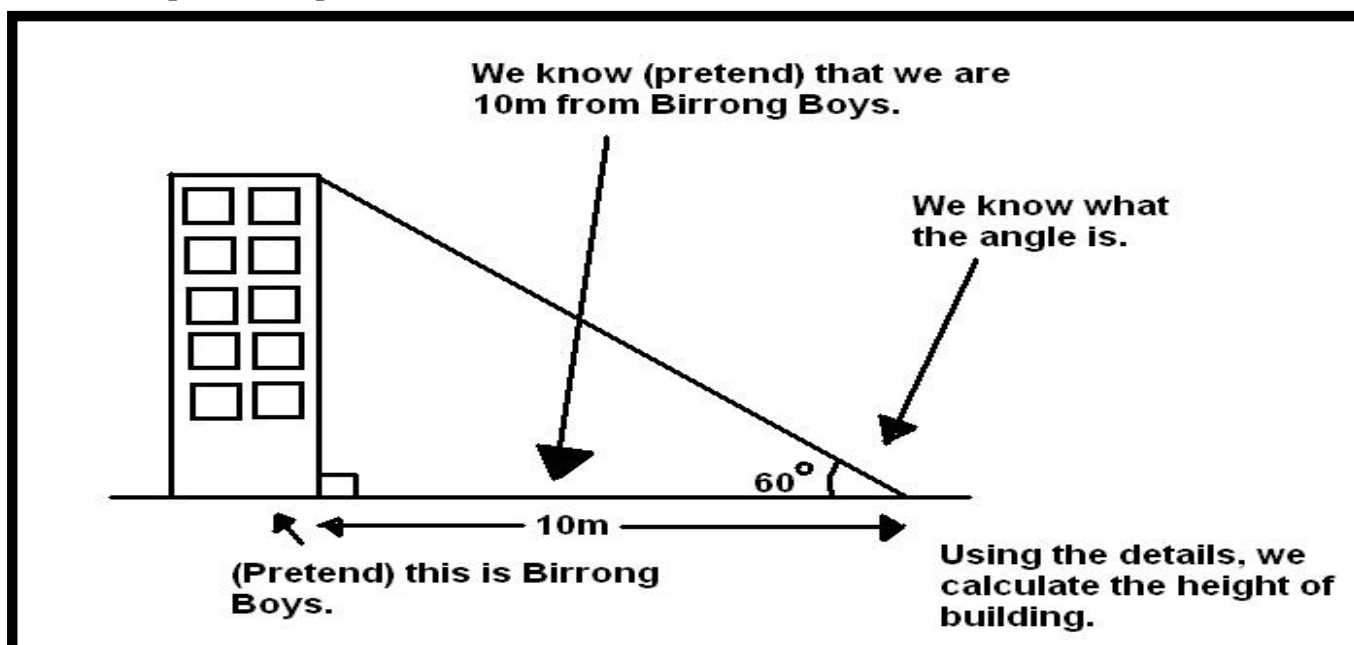

5: Elevation of the building can becalculated by trigonometric functions. https://images.app.goo.gl/UbN3ge5fn9j7K6h58 


\section{PROBABILITY AND STATISTICS APPROACH:}

The other tool named statistics approach also helps in civil works. By using this method, the engineers find out the strength parameters of the structures(Brown \& Hambley)(McDowell \& Humphreys). For example, Rock totals framing a piece of designing structures, for example, dikes, rock fills, heap establishments, and asphalts are exposed to static and dynamic burdens. Because of these heaps smashing happens in two unique structures: scraped spot and molecule discontinuity(Babes, Sdvyzhkova, Larionov, \& Tereshchuk).

Molecule fracture happens when a molecule is exposed to a malleable pressure more noteworthy than its elasticity. This ductile quality is a profound factor boundary. The Weibull statistics can be utilized to portray the fluctuation in the rigidity of rock totals by just utilizing one consistent called the Weibull modulus. This boundary can be utilized not just to depict fluctuation in rigidity yet additionally to portray the impact of size example in elasticity (Lobo-Guerrero \& Vallejo).

The Joint-Probability Method (JPM) was embraced by government offices for basic post-Katrina judgments of tropical storm flood frequencies. In standard JPM executions, it is important to think about countless blends of tempest boundaries, and each such mix (or engineered storm) requires the reproduction of wind, waves, and flood. The instruments used to display the wave, what's more, flood marvels have improved significantly as of late, yet this improvement and the utilization of very huge high-goal lattices have made the calculations both tedious and costly. All together to facilitate the computational weight, two autonomous methodologies have been created to diminish the number of tempest flood reproductions that are required. Both of these purported JPMOS (JPM-Optimal Inspecting) techniques look to precisely cover the whole tempest boundary space through the ideal determination of few boundaries esteems to limit the number of required tempest recreations(Toro, Resio, Divoky, Niedoroda, \& Reed).

On coasts with high flowing reaches, or subject to high floods, both actual water levels and waves can be significant in evaluating flood hazard; their family member significance relies upon the area and on the sort of ocean safeguard. The concurrent event of enormous waves and a high water level is in this way significant in assessing their joined impact on ocean safeguards(Bortot, Coles, \& Tawn). Wave period can likewise be significant in evaluating run-up and overtopping, thus it is helpful likewise to have data on the joint conveyance of wave tallness and period (Hawkes, Gouldby, Tawn, \& Owen).

Except if the factors are either totally autonomous or reliant, multivariate limits are hard to anticipate straightforwardly from observational information, as there might be too scarcely any functions of the important kind among the perceptions. Before, the fitting and extrapolation of the reliance capacities between the factors have regularly included confounded or potentially abstract methodologies (Juang, Jiang, \& Andrus).

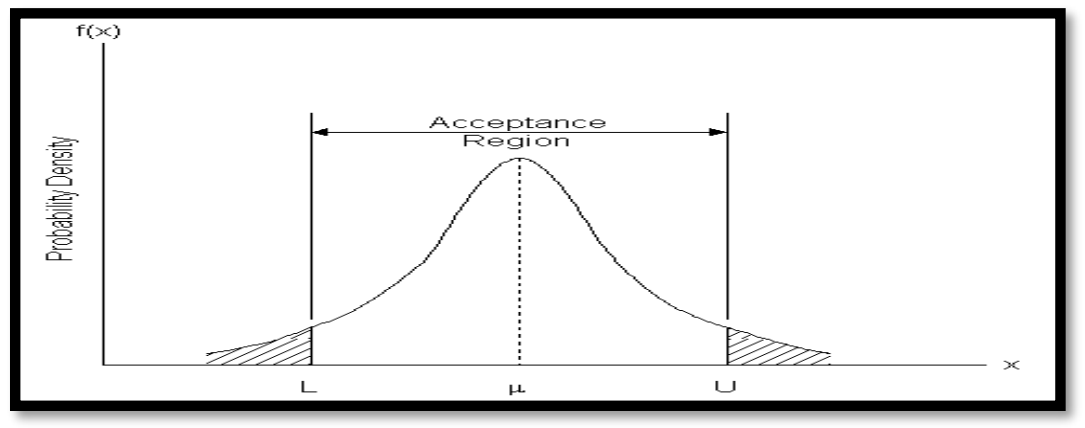

Figure 6: Probability approach in project construction https://images.app.goo.gl/GCn3RmDq2K1yTyTx9

\section{DIFFERENTIAL APPROACH}

Most considerate designing projects require courses indirect variable based math and differential conditions. These courses are essentials for upper-division structural designing courses. Linear and matrix algebra includes the investigation of answers for frameworks of equations, determinants and vector spaces, including capacity spaces, direct changes and quadratic forms (Ghalandari, Shamshirband, Mosavi, \& Chau)Differential equations, is a further developed science course needed by some affable designing projects. It incorporates subjects like first-request differential conditions, unsure coefficients and frameworks of direct differential conditions, with a zero in on applications to science and designing(Buba \& Lee). Plastic consistency is a significant boundary of new cement blends. This exploration examines an AI-based technique for developing useful planning between solid blend properties and plastic consistency. The examined AI technique depends on the help vector relapse (SVR) which is a hearty strategy for a nonlinear and multivariate capacity estimate(Tran, Nguyen, \& Nhat-Duc). 


\section{BEAM DEFLECTION FORMULAS}

\begin{tabular}{|c|c|c|c|}
\hline BEAM TYPE & SLOPE AT ENDS & DEFLECTION AT ANY SECTION IN TERMS OF $x$ & $\begin{array}{c}\text { MAXIMUM AND CENTER } \\
\text { DEFLECTION }\end{array}$ \\
\hline \multicolumn{4}{|c|}{ 6. Beam Simply Supported at Ends - Concentrated load $P$ at the center } \\
\hline 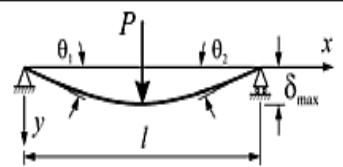 & $\theta_{1}=\theta_{2}=\frac{P l^{2}}{16 E I}$ & $y=\frac{P x}{12 E I}\left(\frac{3 l^{2}}{4}-x^{2}\right)$ for $0<x<\frac{l}{2}$ & $\delta_{\max }=\frac{P l^{3}}{48 E I}$ \\
\hline \multicolumn{4}{|c|}{ 7. Beam Simply Supported at Ends - Concentrated load $P$ at any point } \\
\hline$\overbrace{y}^{+\theta_{1} t} a$ & $\begin{array}{l}\theta_{1}=\frac{P b\left(l^{2}-b^{2}\right)}{6 l E I} \\
\theta_{2}=\frac{P a b(2 l-b)}{6 l E I}\end{array}$ & $\begin{array}{r}y=\frac{P b x}{6 l E I}\left(l^{2}-x^{2}-b^{2}\right) \text { for } 0<x<a \\
y=\frac{P b}{6 l E I}\left[\frac{l}{b}(x-a)^{3}+\left(l^{2}-b^{2}\right) x-x^{3}\right] \\
\text { for } a<x<l\end{array}$ & $\begin{array}{l}\delta_{\max }=\frac{P b\left(l^{2}-b^{2}\right)^{3 / 2}}{9 \sqrt{3} l E I} \text { at } x=\sqrt{\left(l^{2}-b^{2}\right) / 3} \\
\delta=\frac{P b}{48 E I}\left(3 l^{2}-4 b^{2}\right) \text { at the center, if } a>b\end{array}$ \\
\hline \multicolumn{4}{|c|}{ 8. Beam Simply Supported at Ends - Uniformly distributed load $\omega(\mathrm{N} / \mathrm{m})$} \\
\hline$\underset{1}{\stackrel{t}{i} \delta_{\max }}$ & $\theta_{1}=\theta_{2}=\frac{\omega l^{3}}{24 E I}$ & $y=\frac{\omega x}{24 E I}\left(l^{3}-2 l x^{2}+x^{3}\right)$ & $\delta_{\max }=\frac{5 \omega l^{4}}{384 E I}$ \\
\hline \multicolumn{4}{|c|}{ 9. Beam Simply Supported at Ends - Couple moment $M$ at the right end } \\
\hline$\underset{\stackrel{\longrightarrow}{\longrightarrow}}{\stackrel{x}{\longrightarrow}}$ & $\begin{array}{l}\theta_{1}=\frac{M l}{6 E I} \\
\theta_{2}=\frac{M l}{3 E I}\end{array}$ & $y=\frac{M l x}{6 E I}\left(1-\frac{x^{2}}{l^{2}}\right)$ & $\begin{array}{l}\delta_{\max }=\frac{M l^{2}}{9 \sqrt{3} E I} \text { at } x=\frac{l}{\sqrt{3}} \\
\delta=\frac{M l^{2}}{16 E I} \text { at the center }\end{array}$ \\
\hline \multicolumn{4}{|c|}{ 10. Beam Simply Supported at Ends - Uniformly varying load: Maximum intensity $\omega_{0}(\mathrm{~N} / \mathrm{m})$} \\
\hline 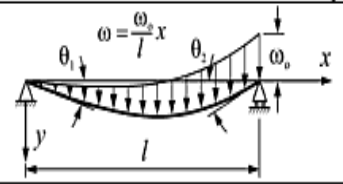 & $\begin{array}{l}\theta_{1}=\frac{7 \omega_{0} l^{3}}{360 E I} \\
\theta_{2}=\frac{\omega_{0} l^{3}}{45 E I}\end{array}$ & $y=\frac{\omega_{0} x}{360 l E I}\left(7 l^{4}-10 l^{2} x^{2}+3 x^{4}\right)$ & $\begin{array}{l}\delta_{\max }=0.00652 \frac{\omega_{a} l^{4}}{E I} \text { at } x=0.519 l \\
\delta=0.00651 \frac{\omega_{a} l^{4}}{E I} \text { at the center }\end{array}$ \\
\hline
\end{tabular}

Figure 8: A differential approach for high rise structures. https://images.app.goo.gl/2DMbX3RQnNyjH7o27

\section{Conclusions}

The conclusion comes out that the Structural designers need to make use ofarithmeticaldeclarations that are acquired from science dependably. Science's circumstances are employed to enumerate the excellence of materials, and authorities must make use of these state of affairs to select the accurate material for a endeavor. Structural designers use geometry frequently when looking over a structure. However, it isn't just significant for mathematicians to comprehend and value this, rehearsing engineers should know about the issues that the normally happening nonlinearities in their frameworks and to improve their comprehension of how their plans work and how they can make them more effective while looking for safety measures. Data show that mathematical instruments are useful in the process of making decisions.

On the other hand, so as to take organizational decisions the calculativetechnique is necessary. In the process of captivating a conclusion,mutually the hypotheticaloutcome and its applicative usefulnessmust be taken into consideration. In practice, the theoretic optimization is not enduringly the ideal decision. To this grade, the execution of animitation is obligatory and to minimize the time deliberated for captivatinga conclusion, a package of programs comes out to be an imperativeaspect. When the tools and mathematical methodologies are taken into consideration for constructing a decision, then the problematicalmethodologyof generating a model to replicate the authenticity becomes a noteworthy problem. The accomplishment of animitation, with real-world applicability to attain maximum optimization as higher as possible, could be envisioned but also captivating into thought other cost-effectiveconditions. The imitationsvalidate that in occasion of assuredforms of products, manufacture in complexnumbers than the providing ones is admitted, and whether the receivers in the arena of civil engineering are instigated, the revenue may be meaningfullyamplified.In most of the subjects 
acknowledged, it is asset observing that the use of mathematics is extensively applied in civil and structural engineering complications. The uncontaminated mathematical connotations seem to be subliminally secreted and entrenched behind the 'civil and structural' of the complications, but it remains appropriate to know wherever diagnostic results originated from. Therefore, it can be accomplished that the mathematics-oriented acute thoughtful fundamentals are suggestively required to crack several civil engineering places of work problems.

\section{References}

1. Aydinlik, S., \& Kiris, A. (2020). Fractional Calculus Approach to Nonlocal Three-Dimensional Vibration Analysis of Plates. AIAA Journal, 58(1), 355-361.

2. Babets, D., Sdvyzhkova, O., Larionov, M., \& Tereshchuk, R. (2017). Estimation of rock mass stability based on probability approach and rating systems. Науковий вісник Національного гірничого університету (2), 58-64.

3. Beardmore, R., Peletier, M. A., Budd, C., \& Wadee, M. A. (2005). Bifurcations of periodic solutions satisfying the zero-Hamiltonian constraint in reversible differential equations. SIAM journal on mathematical analysis, 36(5), 1461-1488.

4. Berton, R. P. (2007). Variational calculation of three-dimensional atmospheric refraction: II. Application to assessment of positioning accuracy. Journal of Optics A: Pure and Applied Optics, 9(7), 603.

5. Bortot, P., Coles, S., \& Tawn, J. (2000). The multivariate gaussian tail model: An application to oceanographic data. Journal of the Royal Statistical Society: Series C (Applied Statistics), 49(1), 31 049.

6. Brown, P. M. B. L. C., \& Hambley, D. F. (2002). Statistics for environmental engineers: Association of Environmental \& Engineering Geologists.

7. Buba, A. T., \& Lee, L. S. (2018). A differential evolution for simultaneous transit network design and frequency setting problem. Expert Systems with Applications, 106, 277-289.

8. Ceylan, A., \& Baykal, O. (2008). Precise height determination using simultaneous-reciprocal trigonometric levelling. Survey Review, 40(308), 195-205.

9. Ghalandari, M., Shamshirband, S., Mosavi, A., \& Chau, K.-w. (2019). Flutter speed estimation using presented differential quadrature method formulation. Engineering Applications of Computational Fluid Mechanics, 13(1), 804-810.

10. Hawkes, P. J., Gouldby, B. P., Tawn, J. A., \& Owen, M. W. (2002). The joint probability of waves and water levels in coastal engineering design. Journal of hydraulic research, 40(3), 241-251.

11. Huh, H., Lim, J., \& Park, S. (2009). High speed tensile test of steel sheets for the stress-strain curve at the intermediate strain rate. International Journal of Automotive Technology, 10(2), 195-204.

12. Jain, M. (2017). Application of Mathematics in civil Engineering. International Journal of Innovation in Engineering and Technology (IJIET), 8(3), 2319-1058.

13. Juang, C. H., Jiang, T., \& Andrus, R. D. (2002). Assessing probability-based methods for liquefaction potential evaluation. Journal of geotechnical and geoenvironmental engineering, 128(7), 580-589.

14. Karakashian, O., \& Makridakis, C. (1999). A space-time finite element method for the nonlinear Schrödinger equation: the continuous Galerkin method. SIAM Journal on Numerical Analysis, 36(6), 1779-1807.

15. Klammler, H., Hatfield, K., Nemer, B., \& Mathias, S. A. (2011). A trigonometric interpolation approach to mixed-type boundary problems associated with permeameter shape factors. Water Resources Research, 47(3).

16. Li, M., Huang, C., \& Wang, P. (2017). Galerkin finite element method for nonlinear fractional Schrödinger equations. Numerical Algorithms, 74(2), 499-525. doi: 10.1007/s11075-016-0160-5

17. Lobo-Guerrero, S., \& Vallejo, L. E. (2006). Application of Weibull statistics to the tensile strength of rock aggregates. Journal of geotechnical and geoenvironmental engineering, 132(6), 786-790.

18. McDowell, G., \& Humphreys, A. (2002). Yielding of granular materials. Granular Matter, 4(1), 1-8.

19. Park, H., Choe, J., \& Kang, J. (2000). Pressure behavior of transport in fractal porous media using a fractional calculus approach. Energy Sources, 22(10), 881-890.

20. Peursem, D., Zlotnik, V., \& Ledder, G. (1999). Groundwater flow near vertical recirculatory wells: effect of skin on flowgeometry and travel times with implications for aquifer remediation. Journal of hydrology, 222(1-4), 109-122.

21. Rossikhin, Y. A., \& Shitikova, M. V. (2010). Application of fractional calculus for dynamic problems of solid mechanics: novel trends and recent results. Applied Mechanics Reviews, 63(1).

22. Toro, G. R., Resio, D. T., Divoky, D., Niedoroda, A. W., \& Reed, C. (2010). Efficient joint-probability methods for hurricane surge frequency analysis. Ocean Engineering, 37(1), 125-134. 
23. Tran, T.-H., Nguyen, H., \& Nhat-Duc, H. (2019). A success history-based adaptive differential evolution optimized support vector regression for estimating plastic viscosity of fresh concrete. Engineering with Computers, 1-14.

24. Wadee, M. A. (2007). Nonlinear mathematics in structural engineering.

25. Wadee, M. A., \& Edmunds, R. (2005). Kink band propagation in layered structures. Journal of the Mechanics and Physics of Solids, 53(9), 2017-2035.

26. Wang, T., Guo, B., \& Xu, Q. (2013). Fourth-order compact and energy conservative difference schemes for the nonlinear Schrödinger equation in two dimensions. Journal of Computational Physics, 243, 382399.

27. Xu, Y., Chen, Y., Guan, X., \& Zhou, J. (2020). Approach to Minimizing the Influence of Changeable Observational Environment on Long-Distance Sea-Crossing Trigonometric Leveling. Journal of Surveying Engineering, 146(4), 04020018.

28. Yang, X.-S. (2017). Mathematics for civil engineers: an introduction: Dunedin Academic Press Ltd. 